\title{
Research Update: Development of Plant-Based Diets for Florida Pompano Trachinotus carolinus
}

\author{
Romi Novriadi $^{1,2}$ and D. Allen Davis ${ }^{1 *}$ \\ ${ }^{1}$ School of Fisheries, Aquaculture and Aquatic Sciences, 203 Swingle Hall, Auburn University, AL 36849, USA \\ ${ }^{2}$ Batam Mariculture Development Center, Directorate General of Aquaculture, Ministry of Marine Affairs and Fisheries, \\ Republic of Indonesia, Indonesia \\ ${ }^{*}$ Corresponding author: davisda@auburn.edu
}

Received: 30 October 2017; Accepted: 03 April 2018

\begin{abstract}
Romi Novriadi and D. Allen Davis. 2018. Research Update: Development of Plant-Based Diets for Florida Pompano Trachinotus carolinus. Aquacultura Indonesiana, 19(2): 47-56. The development of sustainable and economically sound practical diet in the coming years will depend on the reduction of fish meal and the increased inclusion of sustainable protein sources. Over the years, our laboratory has systematically reduced the inclusion levels of fish meal and other animal protein sources by using a range of alternative plantprotein sources. These diets may be further improved through the use of specialized proteins, supplements for limiting amino acids, enzyme and attractants. Good success has been seen with corn protein concentrates, advanced processing products of soybean meal, such as soy protein concentrates, enzyme treated soy and fermented soy. Based on the results of our research, the proportion of animal meal can be reduced to $12 \%$ in our current formulations without any detrimental effects on pompano performance and nutrient retention. In addition, the use of fermented soy or the combination of enzyme-treated soy with proper inclusion level of squid hydrolysates as an attractant has proven to improve the functional properties of soy protein and lead to better liver and intestine condition of pompano. Considering the sizeable body of knowledge concerning nutrition for Florida pompano, all information taken from this species could be used as the starting point to develop better feed formulations for Silver pompano production in Indonesia.
\end{abstract}

Keywords: Alternative protein; Florida pompano; Practical diet; Sustainable

\section{Introduction}

Florida pompano Trachinotus carolinus L., also referred as "pompano" is an excellent mariculture species due to its high market value, readily accepts pelleted feeds, relatively fast growth, and can be cultured in seawater and low salinity environment (Lazo et al., 1998; Weirich and Riley, 2007; Riche and Williams, 2010; Salze et al., 2016). More recently, the pompano industry in the United States has expand as a result of extensive efforts from research institution and private commercial operations to improve the quality and quantity of this highly prized marine fish. Indeed, the success of such an effort is also depends on proper management system to promote an optimum growth of this species. In terms of rearing system, the production of this fish in recirculating systems have received a final rank of "Best Choice" from the Monterey Bay Seafood Watch, which may beneficial to influence public perception and improve the market appeal for pompano (Welch, 2013).

As with many species, a great deal of research has been carried out in an effort to identify nutritional requirements and optimize feed formulations for Florida pompano. In most initial studies, feed for other species were utilized. For example, Tatum (1972), fed the pompano with $40 \%$ protein trout feed supplemented with ground trash fish. Today, studies have been conducted to determine the dietary composition, limiting amino acids, alternative protein sources, attractants, and enzyme that are needed to support the optimal growth of pompano (Lazo et al., 1998; Quintero et al., 2012; Rossi and Davis, 2012; Roe, 2016; Rhodes et al., 2017). Considering the sizeable body of knowledge about the nutrition requirement of the closely-related Florida pompano ( $T$. carolinus), this knowledge may logically be used as a starting point for the development of feeds specific to silver pompano Trachinotus blochii in Indonesia. The use of low-value fish caught from the wild or known as "trash-fish" or commercial aquaculture diet that not specifically designed for pompano during the grow out production, may not be sufficient to meet the basic nutritional requirement for this fish. As the cost of marine feed ingredients continues to increase, it is a top 
priority to replace the expensive meals with less costly ingredients. Thus, we hope that the information taken from our research assembled in this overview paper inspires stakeholder, scientists, and private sector to develop better diet formulation for Silver pompano Trachinotus blochii.

\section{Nutritional Requirements}

Florida pompano-specific work has been initiated and refinements of dietary nutrient specifications led to an optimized crude protein level of $40-44 \%$ with $7-12 \%$ crude lipids (Lazo et al., 1998; Williams et al., 1985; Rossi and Davis, 2012; Rhodes et al., 2017). Requirements of specific amino acids have been quantitatively estimated for taurine at the level of $0.54-0.65 \%$ (Rossi and Davis, 2014a; Salze et al., 2014) and there are gray literature reports for total sulfur amino acids at $1.5 \%$ diet (Patro et al., 2011), as well as lysine at $2.4 \%$ diet (Riche, 2011). These amino acids should satisfy pompano requirement to support optimum growth performance. Albeit information exists for lysine and methionine, these requirements have not been published and it is not clear if taurine was supplemented during these studies. Hence, there may be a need to revisit these requirements. In addition, a few studies have been conducted looking at lipid levels and sources which are typically recommended at $8-12 \%$ of the diets (Lazo et al., 1998; Williams et al., 1985; Rossi and Davis, 2012; Rhodes et al., 2017). Albeit essential fatty acid requirement has not been identified, results indicate that alternative oils can reduce the dependence of fish oil without any detrimental effects on pompano performance (Rombenso et al., 2016; Rombenso et al., 2017; Williams et al., 1985).

\section{Alternative dietary protein}

Fish meal (FM) is often considered as the preferred protein source for aquatic animal feeds because of its high levels of essential amino acids and other essential nutrients (NRC, 2011). However, as the margin decreases, most of the feed manufactures prefer to use an inexpensive ingredients to produce more cost-effective diet (Sookying et al., 2013). Over the years, we have systematically evaluated a number of alternative protein sources to replace fishmeal and other animal proteins allowing increased levels of plant based proteins, such as soybean meal, cotton seed meal, and corn protein concentrate (Cook et al., 2016; Lech and Reigh, 2012; Quintero et al., 2012; Rhodes et al., 2013; Rhodes et al., 2015;
Riche, 2015; Riche and Williams, 2011; Rossi and Davis, 2012; Rossi and Davis, 2014a). This body of research shows that pompano is tolerant to a range of high quality plant-based protein sources that can support good performance of the fish. Across these lines of research, there is a clear reduction of fish performance when animal meal is reduced to low levels. Based on current knowledge, animal proteins must be maintained at $12 \%$ of the pompano diet to yield good growth performance. In such diets, taurine is typically the first-limiting amino acid and must be supplemented.

Soybean meal (SBM) possesses many of the qualities required to be a viable alternative to fish meal and has been previously shown to support Florida pompano growth (Lech and Reigh, 2012). Soybean meal is widely available, highly digestible, easily shipped and stored, and priced competitively with other plant-based food sources (Davis and Arnold, 2000, Gatlin et al., 2007, Amaya et al., 2007). In addition, soybean meal has a favorable amino acid profile with exception of lysine and total sulfur-based amino acids (methionine + cystine) and reported to have an apparent energy and protein digestibility for Florida pompano of 67.4 and $84.3 \%$, respectively (Gothreaux et al., 2010). However, as mentioned earlier, wider use of SBM may be hindered by negative effects associated with the presence of anti-nutritional factors (ANFs), such as lectins, phytic acid, saponins, phytosterols, and allergens (NRC, 2011), which is responsible for the decreased growth performance (Tibaldi et al., 2006), feed efficiency (Olli et al., 1995) and histomorphological change in the distal intestinal (Rumsey et al., 1994, Nordrum et al., 2000) of some species of fish. In addition, phosphorus deficiency may also play a role in the decreased performance of fish fed with elevated level of soy protein. Consequently, there will be most likely a need to use a variety of advanced processing products of soybean in combination with enzyme, such as phytase, to provide better nutritional value, digestibility and nutrient retention for pompano.

Several advanced processing products of SBM that are considered a promising alternative for the substitution of animal meal are soy protein concentrate (SPC), enzyme-treated soy (ESBM), and fermented soybean meal (FSBM). Along with protein, the use of attractants or palatability enhancer as nonnutritive ingredients are also required to enhance the utilization of plant-based diet (Nunes et al., 2006). Several 
studies have reported that the use of krill meal (Gaber, 2005), blue mussel meal (Nagel et al., 2014), tuna by-product meal (Hernández et al., 2011), algal meal (Kissinger et al., 2016), nucleotides (Barnard, 2006) and chemo-attractants derived from hydrolysis process of seafood waste and by-products (Refstie et al., 2004, Barry et al., 2017) could be viewed as attractants to enhance the use of high plant-based diet formulation. Rhodes et al. (2017a) demonstrated that the use of attractants could be used in combination with soy-protein to develop the practical diet and enhance the growth performance of pompano.

\section{Soy protein concentrate}

Soy protein concentrate (SPC) produced from high quality, dehulled soybean seeds by removing most of the oil and water soluble nonprotein constituents have been shown to have lower amount of ANFs compared to SBM (Sookying, 2010). Moreover, this process also improve the nutritional value in SPC and contains approximately $65 \%$ crude protein which is similar to that found in FM, and considerably higher than that of SBM (Liu, 2012, Paripatananont et al., 2001). The uses of SPC as a protein source in aquaculture diets have received considerable attention with satisfactory results (Kaushik et al., 1995, Mambrini et al., 1999). For pompano, research on the use of SPC as dietary protein sources also produce a good results and was summarized in Quintero et al. (2012). Results of the study demonstrated that the inclusion of SPC at the level of $12-20 \%$ to replace FM in soybased diet did not cause any palatability problems and the diet was readily consumed by pompano. In addition, SPC also improve the nutritional value of SBM as the growth performance of pompano increased with increasing inclusion level of SPC.

To identify the possible restrictions in high soy diets, the efficacy of SPC was also observed with the presence of phosphorus (P) and methionine (M). The use of synthetic methionine or mixing with other protein source is recommended to counter the low levels of methionine found in SBM (Sookying et al., 2013). The results of the study indicated that fish offered diets with high inclusion of SPC in combination with $\mathrm{P}$ and $\mathrm{M}$ resulted in higher final weights, higher biomass, and higher growth rate than fish fed without inclusion of SPC and 30\% FM. Indeed, the ability of SPC in combination with $\mathrm{P}$ and $\mathrm{M}$ to facilitate the reduction of dietary FM from $30 \%$ to $15 \%$ is a step toward a more sustainable and economical diet for pompano production.
Improving the efficacy of high soy feed formulations with SPC for pompano also have been investigated. Rossi and Davis (2012) were able to completely replace animal meal using combination of SBM and SPC as the dietary protein sources supplemented with taurine. In this research, there were no statistical differences in terms of final weight, percentage weight gain, thermal growth coefficient, survival and FCR when $15 \%$ of animal meal replaced by SPC supplemented with taurine. According to NRC (2011), taurine appears to be a major contributor to osmotic pressure balance in some animals and their biosynthesis appears to be very low in some species. It has been shown that taurine supplementation can enhance pompano growth and survival (Rossi and Davis, 2012, Rossi and Davis, 2014b). As the use of plant-based source to produce economicallysound and sustainable aquaculture diet increase, taurine supplementation in combination with SPC is required to optimize the production (Salze and Davis, 2015).

\section{Enzyme treated soy}

Another alternative protein source for replacing FM in feed formulation is enzymetreated soybean meal (ESBM) produced through a series of non-alcohol extraction process and enzymatic treatment from high quality de-hulled soybeans. According to Amezquita and Arana (2015), ESBM contain higher levels of protein, low oligosaccharides and minimal levels of soy ANFs. To evaluate the potential of this alternative soy protein, a 56-days growth trial was conducted in combination with squid products. As mentioned earlier about the use of feeding stimulants, squid meal and squid hydrolyzate were also evaluated in this study by using combination of ESBM and SBM as the primary protein source. Results of the study highlighted that the supplementation of squid hydrolyzate at the level of $4 \%$ were able to improve the efficacy of soy-based diet and yielded similar growth to those fish fed with $15 \%$ poultry by-product meal (PBM) as the reference diet.

The inclusion of a high amount of SBM in formulated diets has been reported to induce inflammation in the distal intestine of some species of fish (Urán et al., 2009, Nordrum et al., 2000, Refstie et al., 2000). The symptoms are characterized by increased amount of connective tissue; a profound infiltration of inflammatory cells in the lamina propria (Krogdahl et al., 2000, Refstie et al., 2000), a reduced number of supranuclear vacuoles in the absorptive epithelium (Trushenski. 2015); and increase in 
the number of goblet cells ( $\mathrm{Ng}$ et al., 2005, Oehlers et al., 2011). In our recent study, the use of ESBM and squid products to completely replace PBM on the histological condition of Florida pompano has been evaluated. Based on the histological sections of fish liver shown in Figure 1, the supplementation of $4 \%$ squid hydrolyzate $(\mathrm{SH})$ in combination with ESBM and SBM as the primary protein sources partly improve the liver condition of fish with lower score for vacuolization, nuclear change and glycogen accumulation similar to those fish fed with PBM. Regarding to the distal intestine analysis, typical changes were apparent after $56 \mathrm{~d}$ of feeding trial. The lamina propria (LP) thickness of mucosal folds was decreased with an increase of cellular infiltration in the distal intestine of fish fed with basal diet in comparison to fish fed with $4 \%$ SH and PBM diet. Regarding the goblet cells (GC), differences were noted between basal and PBM. Based on these results, combination of ESBM and SH has the potential to serve as an alternative protein source and attractant to improve the growth performance of pompano (Novriadi et al., 2017a).

\section{Fermented Soy}

The use of microorganisms for solid state fermentation of SBM has been proven to be an alternative method to improve the functional properties and nutritional quality of SBM, reduce
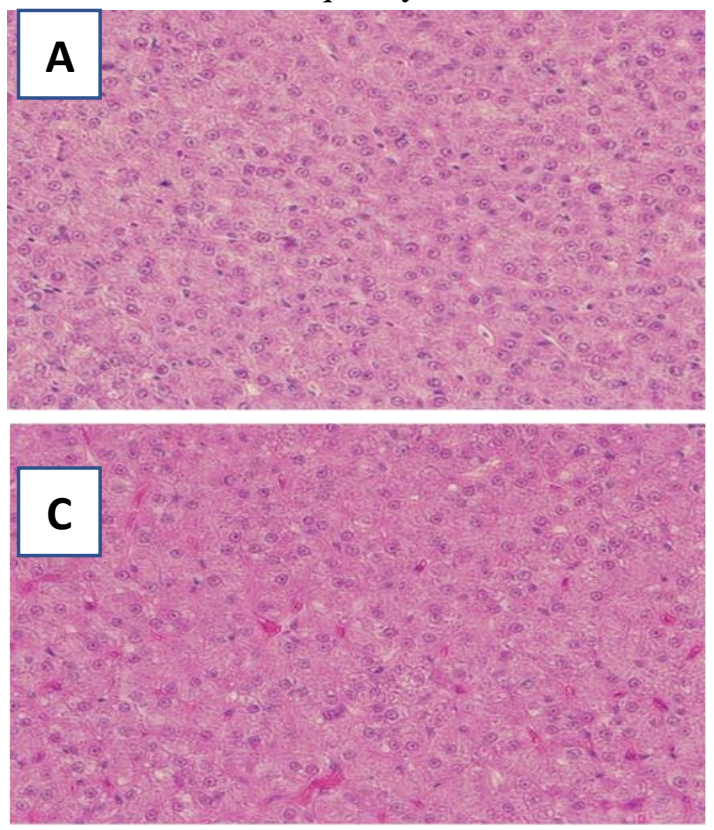

the anti nutrients, and increase the content of soybean peptides (Papagianni et al., 1999, Hong et al., 2004, Bi et al., 2015, Novriadi 2017c). Zhuo et al. (2014) suggested that fermentation process with Lactobacillus spp. can improve the crude protein digestibility and dry matter of SBM for grouper Epinephelus coioides. Other than Lactobacillus spp., several microorganisms can be used to facilitate the fermentation process and decrease the antinutrients, such as Aspergillus ficuum and Aspergillus oryzae (Chen et al., 2016), Bacillus subtilis (Azarm and Lee, 2014), Lactobacillus plantarum P8 (Wang et al., 2016) or with the combination of Bacillus spp. and Aspergillus spp. (Barnes et al., 2014). Study from Yamamoto et al. (2010) indicated that with proper inclusion level, fermented soybean meal (FSBM) is beneficial for preventing various physiological abnormalities and restores the condition of the lamina propria of mucosal folds in the distal intestine of rainbow trout Oncorhynchus mykiss and results in intestinal histology similar to conditions in fish fed a FM diet. Since fermentation could also be applied to eliminate a variety of ANFs (Papagianni et al., 1999), improve the nutritional quality and bioactivity of SBM (Chi and Cho, 2016), and help to improve the morphological conditions of liver and distal intestine of the fish (Yamamoto et al., 2010), there are a great potential of replacing SBM with FSBM for pompano.
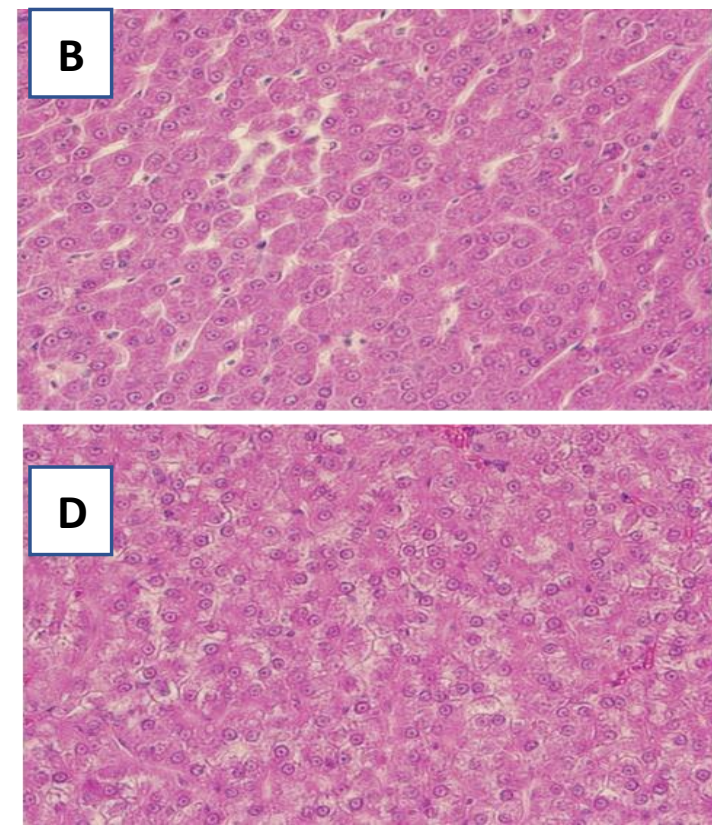

Figure 1. Representative histopathological images of hematoxylin and eosin-stained sections of liver from Florida pompano after $56 \mathrm{~d}$ of being fed with (A) 15\% animal meal, (B) basal diet $(47.2 \%$ soybean meal, $14,8 \%$ enzyme-treated soy, and $8 \%$ corn protein concentrate), (C) $4 \%$ squid hydrolysate added into basal diet, and (D) $4 \%$ squid meal added into basal diet (the reader is referred to Novriadi et al., 2017a, for details) 
To investigate the effect of FSBM, a 56days growth trial was conducted in a semirecirculation system in 2016. Results of this study indicated that fish fed with diet containing FSBM at the level of 20, 30 and $41 \%$, replacing 50 (FSBM 50), 75 (FSBM 75) and 100\% (FSBM 100 ) of the solvent extracted SBM attained similar growth performance, serum levels and enzyme activities, such as total protein, albumin, glucose, bile acid, plasma alkaline phosphatase (ALP), alanine aminotransferase (ALT), and aspartate aminotransferase (AST) activities. However, the microbial fermentation process to produce FSBM used in this research was able to improve the functional properties of SBM and lead to better liver and intestine condition of pompano (Novriadi et al., 2017b)

The histological examination of fish liver presented in Table 1 indicated that fish fed with basal diet, consisting with SBM showed a higher score for glycogen granulation, inflammation, and nuclear change (Table 1 and Figure 2). Interestingly, $50 \%$ replacement of SBM with FSBM resulted with better condition compared to fish fed with basal diet. Fish fed with FSBM 75 presented less inflammation with cells having a moderate level of glycogen accumulation. Fish fed with FSBM 100 appear to be in a better condition compared to other dietary treatment, albeit little glycogen granulation still present in the cells. At the end of the trial, with the taurine supplementation, all dietary treatment did not show any incidence of green liver. The administration of experimental diet was significantly affect the morphology of intestines. In distal tract of intestine (Figure 2 and Table 1), fish fed with basal diet and FSBM showed an abundance number of goblet cells (GC). The width of the lamina propria (LP) and cellularity in the distal intestine of fish fed basal diet is wider compared to FSBM 75 and FSBM 100. The structure of the LP in fish fed with FSBM 75 was thinner with slightly less cellularity area compared to fish fed with basal and FSBM 50. The LP of fish fed with FSBM 100 showing a better condition compared to other dietary treatments (Novriadi et al., 2017b).

\section{Corn protein concentrate}

Other than soy protein, corn protein concentrate (CPC) is also utilized as feed ingredients to develop practical diets for pompano. Corn gluten meal or CPC are excellent representations of ingredients that balance amino acid profile of soybean meal, which is the dominant plant protein source used in feed formulations. For example, in our laboratories, we have used these meals to help balance the amino acids profile on practical diets for Florida pompano, Pacific white shrimp (Litopenaeus vannamei), White seabass (Atractoscion nobilis), and California yellowtail (Seriola lalandi), resulted in a good performance (Sookying, 2010, Rhodes et al., 2017a). According to Phillips and Sternberg (1979), CPC is rich in methionine and cystine and able to enhanced the nutritive value of dietary treatment when combined with soy products. Based on the recently completed research, the development of soy-based diet containing CPC up to $15 \%$ appears do not have any palatability problem to pompano and provide a similar performance to the pompano fed with $15 \%$ animal meal.

\section{Cottonseed meal}

Because of the interest in reducing feed costs, considerable effort is being made in evaluating and demonstrating the applicability of other plant-based ingredient, such as cottonseed meal (CSM). Several studies reported that CSM can be used to replace FM in certain levels for catfish, carp and tilapia (Mbahinzireki et al., 2001, Robinson and Li, 2008, Cai et al.,2011). However, as summarized by NRC (2011), the main concern on utilizing CSM is the risk of gossypol toxicity that limit the nutrient digestibility. Dorsa et al. (1982) noted that liver exhibits the most severe effects and highest concentrations of gossypol. Two main symptoms are exhibited when faced with an increase in gossypol, including the diffusing of coagulative necrosis and hepatocellular vacuolization, a loss of cell structure (Evans et al., 2010, Francis et al., 2001). To further evaluate the effect of FM replacement with CSM in the development of practical diet for pompano, two growth trials were conducted, one testing the inclusion levels of cottonseed meal replacing $0 \%, 25 \%, 75 \%$, and $100 \%$ of fish meal in the diets for Florida pompano with and without lysine supplementation, and one to test cottonseed flours produced by varying processes.

Results of the study as summarized in Cook et al. (2016) demonstrated that fish fed diets with the highest level of CSM and reduced FM levels produced poor results. However, the growth performance of pompano is partially remediated through the use of lysine suplementation into the diet. The proper inclusion level of CSM also did not show any difference in 
terms of liver cells and vacuolization, indicating a reduction of gossypol toxicity effect to the fish liver. As the conclusion, inclusion of CSM up to $20 \%$ with the addition of lysine may be used to develop practical diet for Florida pompano without any negative impact to the growth performance of fish. This study is very important to provide information about the probability of utilizing CSM to replace FM in developing costeffective feed for pompano.

Table 1. Diagnostic features of liver and distal intestine of fish as a response to various inclusion level of fermented soybean meal (FSBM). Results presented as mean \pm standard deviation $(n=12)$. Results in the same row with different superscript letter are significantly different $(\mathrm{P}<0.05)$ based on Welch's one-way analysis of variance followed by Games-Howell post hoc tests to determine significant differences between treatments (the reader is referred to Novriadi et al., $2017 \mathrm{~b}$, for details).

\begin{tabular}{|c|c|c|c|c|c|}
\hline \multirow{2}{*}{ Feature } & \multicolumn{4}{|c|}{ Experimental diet } & \multirow{2}{*}{ P-value } \\
\hline & Basal & FSBM $50^{1}$ & FSBM $75^{2}$ & FSBM $100^{3}$ & \\
\hline \multicolumn{6}{|l|}{ Intestine } \\
\hline Goblet cells & $4.2 \pm 0.4^{\mathrm{a}}$ & $3.8 \pm 0.5^{\mathrm{a}}$ & $2.4 \pm 0.5^{\mathrm{b}}$ & $2.3 \pm 0.5^{\mathrm{b}}$ & $<0.0001$ \\
\hline Cellular infiltration & $3.8 \pm 0.4^{\mathrm{a}}$ & $3.7 \pm 0.5^{\mathrm{a}}$ & $2.4 \pm 0.5^{\mathrm{b}}$ & $2.0 \pm 0.4^{\mathrm{c}}$ & $<0.0001$ \\
\hline Lamina Propria width & $3.8 \pm 0.5^{\mathrm{a}}$ & $3.8 \pm 0.4^{\mathrm{a}}$ & $2.4 \pm 0.5^{\mathrm{b}}$ & $2.1 \pm 0.4^{\mathrm{b}}$ & $<0.0001$ \\
\hline \multicolumn{6}{|l|}{ Liver } \\
\hline Glycogen granulation & $4.1 \pm 0.4^{\mathrm{a}}$ & $3.6 \pm 0.5^{\mathrm{b}}$ & $2.4 \pm 0.5^{\mathrm{c}}$ & $2.0 \pm 0.0^{\mathrm{d}}$ & $<0.0001$ \\
\hline Inflammation & $3.9 \pm 0.3^{\mathrm{a}}$ & $3.3 \pm 0.5^{\mathrm{b}}$ & $2.4 \pm 0.4^{\mathrm{c}}$ & $1.8 \pm 0.2^{\mathrm{d}}$ & $<0.0001$ \\
\hline Nuclear change & $3.8 \pm 0.1^{\mathrm{a}}$ & $3.2 \pm 0.4^{\mathrm{b}}$ & $2.3 \pm 0.5^{\mathrm{c}}$ & $1.8 \pm 0.3^{\mathrm{d}}$ & $<0.0001$ \\
\hline \multicolumn{6}{|c|}{$\begin{array}{l}\text { FSBM: Fermented Soybean Meal (PepSoyGen, Nutraferma, Protein and Biotech Products, Sioux City, IA, } \\
\text { USA) }\end{array}$} \\
\hline \multicolumn{6}{|c|}{2 Basal: $15 \%$ animal diet, $47.2 \%$ dehulled soybean meal (SBM), and $6.3 \%$ corn protein concentrate } \\
\hline \multicolumn{6}{|c|}{3 FSBM 50: 50\% replacement of SBM with FSBM } \\
\hline \multicolumn{6}{|c|}{$4 \quad$ FSBM 75: 75\% replacement of SBM with FSBM } \\
\hline \multicolumn{6}{|c|}{5 FSBM 100: $100 \%$ replacement of SBM with FSBM } \\
\hline
\end{tabular}
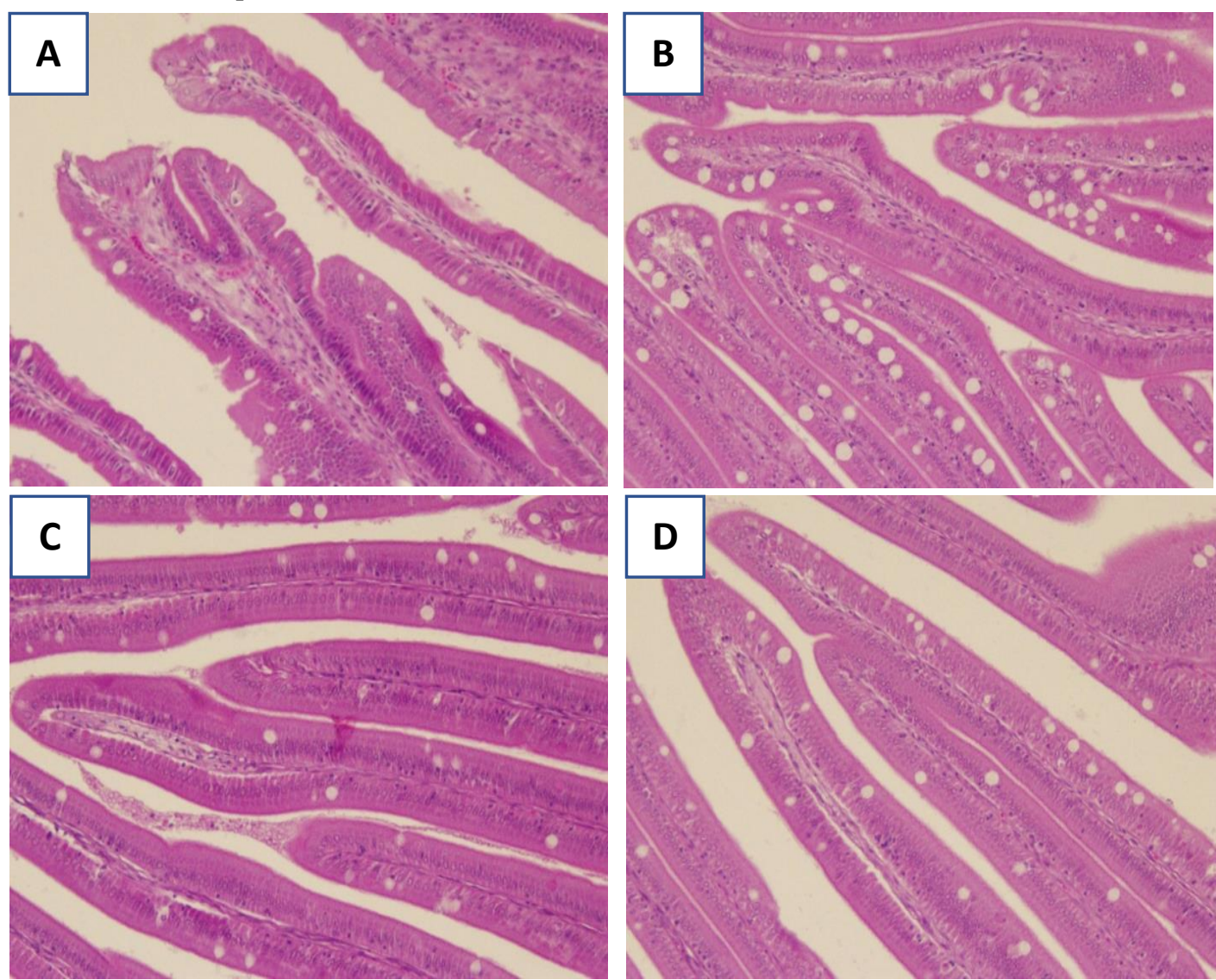

Figure 2. Representative histopathological images of hematoxylin and eosin-stained sections of distal intestines from Florida pompano after $56 \mathrm{~d}$ of being fed with (A) basal diet (B) FSBM 50 (C) FSBM 75, and (D) FSBM 100 (the reader is referred to Novriadi et al., 2017b, for details) 


\section{Conclusion}

In response to the expansion of global aquaculture, research efforts to produce proper and economically sound food formulation are very important. The nutrient requirements and types of ingredients presented in this paper represent the dietary requirement to support normal growth and physiological response of pompano. Based on previous research in our laboratory, several alternative plant-protein sources could be used to replace the dietary fish meal in the soy-based diet, such as soybean meal and cottonseed meal. However, supplementation with attractant, amino acid, enzyme, corn protein concentrates and the use of advanced processing products of SBM, such as soy protein concentrate, enzyme-treated soy, and fermented soy may be needed to improve the efficacy of plant protein-based diet.

\section{References}

Amaya, E., D.A. Davis, and D.B. Rouse. 2007 Alternative diets for the Pacific white shrimp Litopenaeus vannamei. Aquaculture, 262: 419-425.

Amezquita, J. and E. Arana. 2015. Evaluation of SPC as a partial substitute for fish meal in the diet for Striped bass in Todos Santos Island, Baja California, Mexico. Technical report to U.S. Soybean Export Council.

Azarm, H.M. and S.M. Lee. 2014. Effects of partial substitution of dietary fish meal by fermented soybean meal on growth performance, amino acid and biochemical parameters of juvenile black sea bream Acanthopagrus schlegeli. Aquaculture Research, 45: 994-1003.

Barnard, P. 2006. Gustatory and olfactory feeding responces in Japanese koi carp (Cyprinus carpio). University of Stellenbosch, Stellenbosch.

Barnes, M.E., M.L. Brown, T. Bruce, S. Sindelar, and R. Neiger. 2014. Rainbow trout rearing performance, intestinal morphology, and immune response after long-term feeding of high levels of fermented soybean meal. North American Journal of Aquaculture, 76: 333-345.

Barry, K.J., R.I. McClure, and J.T. Trushenski. 2017. Sea clam-derived feeding stimulants enhance acceptability and intake of reduced fish meal, soy-based sunshine bass feeds. North American Journal of Aquaculture, 79: 115-122.

Bi, H., H. Zhao, F. Lu, C. Zhang, X. Bie, and Z. Lu. 2015. Improvement of the nutritional quality and fibrinolytic enzyme activity of soybean meal by fermentation of Bacillus subtilis. Journal of Food Processing and Preservation, 39: 1235-1242.

Cai, C., E. Li, Y. Ye, A. Krogdahl, G. Jiang, Y. Wang, and L. Chen. 2011. Effect of dietary graded levels of cottonseed meal and gossypol on growth performance, body composition and health aspects of allogynogenetic silver crucian carp, Carassius auratus gibelio $9 \times$ Cyprinus carpio $\mathrm{O}^{\widehat{T}}$. Aquaculture nutrition, 17(4): 353-360.

Chen, L., P.V. Vadlani, R.I. Madl, and W. Gibbons. 2016. Degradation of phytic acid and soy protein in soy meal via cofermentation of Aspergillus oryzae and Aspergillus ficuum. Journal of the American Oil Chemists' Society, 93: 45-50.

Chi, C.H. and S.J. Cho. 2016. Improvement of bioactivity of soybean meal by solid-state fermentation with Bacillus amyloliquefaciens versus Lactobacillus spp. and Saccharomyces cerevisiae. LWTFood Science and Technology, 68: 619625.

Cook, R.L., Y. Zhou, M.A. Rhodes, and D.A. Davis. 2016. Evaluation of various cottonseed products on the growth and digestibility performance in Florida pompano Trachinotus carolinus. Aquaculture, 453: 10-18.

Davis, D.A. and C. Arnold. 2000. Replacement of fish meal in practical diets for the Pacific white shrimp, Litopenaeus vannamei. Aquaculture, 185: 291-298.

Dorsa, W. J., H.R. Robinette, E.H. Robinson, and W.E. Poe. 1982. Effects of dietary cottonseed meal and gossypol on growth of young channel catfish. Transactions of the American Fisheries Society, 111(5): 651655.

Evans, J.J., D.J. Pasnik, M. Yildirim-Aksoy, C. Lim, and P.H. Klesius. 2010. Histologic changes in channel catfish, Ictalurus punctatus Rafinesque, fed diets containing graded levels of gossypol-acetic acid. Aquaculture Nutrition, 16(4): 385-391.

Francis, G., H.P. Makkar, and K. Becker. 2001. Antinutritional factors present in plantderived alternate fish feed ingredients and their effects in fish. Aquaculture, 199(3-4): 197-227.

Gaber, M. 2005. The effect of different levels of krill meal supplementation of soybean-based diets on feed intake, digestibility, and chemical composition of juvenile nile tilapia Oreochromis niloticus L. Journal of the World Aquaculture Society, 36: 346353. 
Gatlin, D.M., F.T. Barrows, P. Brown, K. Dabrowski, T.G. Gaylord, R.W. Hardy, E. Herman, G. Hu, A. Krogdahl, and R. Nelson. 2007. Expanding the utilization of sustainable plant products in aquafeeds: a review. Aquaculture research, 38: 551579.

Gothreaux, C.T., R.C. Reigh, M.B. Williams, and E.J. Chesney. 2010. Amino acid availability of soybean meal for Florida pompano. North American Journal of Aquaculture, 72: 309-313.

Hernández, C., M.A. Olvera-Novoa, D.M. Smith, R.W. Hardy, and B. GonzalezRodriguez. 2011. Enhancement of shrimp Litopenaeus vannamei diets based on terrestrial protein sources via the inclusion of tuna by-product protein hydrolysates. Aquaculture, 317:117-123.

Hong, K.J., C.H. Lee, and S.W. Kim. 2004. Aspergillus oryzae GB-107 fermentation improves nutritional quality of food soybeans and feed soybean meals. Journal of medicinal food, 7: 430-435.

Kaushik, S., J. Cravedi, J. Lalles, J. Sumpter, B. Fauconneau, and M. Laroche. 1995. Partial or total replacement of fish meal by soybean protein on growth, protein utilization, potential estrogenic or antigenic effects, cholesterolemia and flesh quality in rainbow trout, Oncorhynchus mykiss. Aquaculture, 133: 257-274.

Kissinger, K.R., A. García-Ortega, and J.T. Trushenski. 2016. Partial fish meal replacement by soy protein concentrate, squid and algal meals in low fish-oil diets containing Schizochytrium limacinum for longfin yellowtail Seriola rivoliana. Aquaculture, 452: 37-44.

Krogdahl, A., A. Bakke-McKellep, K. Roed, and G. Baeverfjord. 2000. Feeding Atlantic salmon Salmo salar L. soybean products: effects on disease resistance (furunculosis), and lysozyme and IgM levels in the intestinal mucosa. Aquaculture Nutrition, 6: $77-84$

Lazo, J.P., D.A. Davis, and C.R. Arnold. 1998. The effects of dietary protein level on growth, feed efficiency and survival of juvenile Florida pompano (Trachinotus carolinus). Aquaculture, 169: 225-232.

Lech, G.P. and Reigh, R.C. 2012. Plant products affect growth and digestive efficiency of cultured Florida pompano (Trachinotus carolinus) fed compounded diets. PLoS One, 7:e34981.

Liu, K. 2012. Soybeans: Chemistry, Technology, And Utilization, Springer.

Mambrini, M., A.J. Roem, J. Carvedi, J. Lalles, and S. Kaushik. 1999. Effects of replacing fish meal with soy protein concentrate and of DL-methionine supplementation in high-energy, extruded diets on the growth and nutrient utilization of rainbow trout, Oncorhynchus mykiss. Journal of animal science, 77: 2990-2999.

Mbahinzireki, G.B., K. Dabrowski, K.J. Lee, D. ElSaidy, and E.R. Wisner. 2001. Growth, feed utilization and body composition of tilapia (Oreochromis sp.) fed cottonseed meal-based diets in a recirculating system. Aquaculture Nutrition, 7(3), 189200.

Nagel, F., A. Danwitz, M. Schlachter, S. Kroeckel, C. Wagner, and C. Schulz. 2014. Blue mussel meal as feed attractant in rapeseed protein-based diets for turbot (Psetta maxima L.). Aquaculture Research, 45: 1964-1978.

Ng, A.N., T.A. de Jong-Curtain, D.J. Mawdsley, S.J. White, J. Shin, B. Appel, P.D.S Dong, D.Y. Stainier, and J.K. Heath. 2005. Formation of the digestive system in zebrafish: III. Intestinal epithelium morphogenesis. Developmental biology, 286:114-135.

Nordrum, S., A. Bakke-McKellep, A. Krogdahl, and R. Buddington. 2000. Effects of soybean meal and salinity on intestinal transport of nutrients in Atlantic salmon (Salmo salar L.) and rainbow trout (Oncorhynchus mykiss). Comparative Biochemistry and Physiology Part B: Biochemistry and Molecular Biology, 125:317-335.

Novriadi, R., E. Spangler, M. Rhodes, T. Hanson, and D.A. Davis. 2017a. Effects of various levels of squid hydrolysate and squid meal supplementation with enzyme-treated soy on growth performance, body composition, serum biochemistry and histology of Florida pompano Trachinotus carolinus. Aquaculture, 481:85-93.

Novriadi, R., M. Rhodes, M. Powell, T. Hanson, and D.A. Davis. 2017b. Effects of soybean meal replacement with fermented soybean meal on growth, serum biochemistry and morphological condition of liver and distal intestine of Florida pompano Trachinotus carolinus. Aquaculture Nutrition, 24(3): 110 .

Novriadi, R. 2017c. A Meta-analysis approach toward fish meal replacement with fermented soybean meal: effects on fish growth performance and feed conversion ratio. Asian Fisheries Science, 30: 227244.

NRC (National Research Council), 2011. Nutrient Requirements of Fish and Shrimp. National Academy Press. Washington, D.C., USA 
Nunes, A.J., M.V. Sá, F.F. Andriola-Neto, and D. Lemos. 2006. Behavioral response to selected feed attractants and stimulants in Pacific white shrimp, Litopenaeus vannamei. Aquaculture, 260: 244-254.

Oehlers, S.H., M.V. Flores, K.S. Okuda, C.J. Hall, K.E. Crosier, and P.S. Crosier. 2011. A chemical enterocolitis model in zebrafish larvae that is dependent on microbiota and responsive to pharmacological agents. Developmental Dynamics, 240: 288-298.

Olli, J., A. Krogdahl, and A. Våbenø. 1995. Dehulled solvent-extracted soybean meal as a protein source in diets for Atlantic salmon, Salmo salar L. Aquaculture Research, 26:167-174.

Papagianni, M., S.E. Nokes, and K. Filer. 1999. Production of phytase by Aspergillus niger in submerged and solid-state fermentation. Process Biochemistry, 35:397-402.

Paripatananont, T., M. Boonyaratpalin, P. Pengseng, and P. Chotipuntu. 2001. Substitution of soy protein concentrate for fishmeal in diets of tiger shrimp Penaeus monodon. Aquaculture research, 32:369-374.

Patro, B., R. Reigh, and M. Williams. 2011. Dietary methionine requirement of Florida pompano In Aquaculture America 2011. New Orleans, USA.

Phillips, R.D. and M. Sternberg. 1979. Corn protein concentrate: functional and nutritional properties. Journal of Food Science, 44: 1152-1155.

Quintero, H.E., D.A. Davis, and M.A. Rhodes. 2012. Soy protein concentrate as an alternative ingredient in Florida Pompano (Trachinotus carolinus) diets. Journal of Applied Aquaculture, 24:247-261.

Refstie, S., Ø.J. Korsøen, T. Storebakken, G. Baeverfjord, I. Lein, and A.J. Roem. 2000. Differing nutritional responses to dietary soybean meal in rainbow trout (Oncorhynchus mykiss) and Atlantic salmon (Salmo salar). Aquaculture, 190:49-63.

Refstie, S., J.J. Olli, and H. Standal. 2004. Feed intake, growth, and protein utilisation by post-smolt Atlantic salmon (Salmo salar) in response to graded levels of fish protein hydrolysate in the diet. Aquaculture, 239: 331-349.

Rhodes, M., Y. Zhou, G. Salze, T. Hanson, and D. Davis. 2017a. Development of plant based diets and the evaluation of dietary attractants for juvenile Florida pompano, Trachinotus carolinus L. Aquaculture Nutrition, 23(5): 1065-1075.

Rhodes, M.A., T. Hanson, S. Alavi, and A.D. Davis. 2013. High-soy, fishmeal-free diets support Florida pompano growth In Global
Aquaculture Advocate, St. Louis, Missouri, Vol. September /October, pp. 96-99.

Rhodes, M.A., Y. Zhou, and D.A. Davis. 2015. Use of dried fermented biomass as a fish meal replacement in practical diets of Florida Pompano, Trachinotus carolinus. Journal of Applied Aquaculture, 27: 29-39.

Rhodes, M.A., Y. Zhou, G.P. Salze, T.R. Hanson, and A.D. Davis. 2017b. Development of plant-based diets and the evaluation of dietary attractants for juvenile Florida pompano, Trachinotus carolinus L. Aquaculture Nutrition, 23(5): 1065-1075

Riche, M. 2011. Estimated quantitative amino acid requirements for Florida pompano reared in low-salinity environments In Aquaculture America 2011. World Aquaculture Society, New Orleans, LA.

Riche, M. 2015. Nitrogen utilization from diets with refined and blended poultry by-products as partial fish meal replacements in diets for low-salinity cultured Florida pompano, Trachinotus carolinus. Aquaculture, 435: 458-466.

Riche, M. and T. Williams. 2010. Apparent digestible protein, energy and amino acid availability of three plant proteins in Florida pompano, Trachinotus carolinus L. in seawater and low salinity water. Aquaculture Nutrition, 16: 223-230.

Riche, M. and T.N. Williams. 2011. Fish meal replacement with solvent-extracted soybean meal or soy protein isolate in a practical diet formulation for Florida pompano (Trachinotus carolinus, L.) reared in low salinity. Aquaculture Nutrition, 17: 368-379.

Robinson, E.H. and M.H. Li. 2008. Replacement of soybean meal in channel catfish, Ictalurus punctatus, diets with cottonseed meal and distiller's dried grains with solubles. Journal of the World Aquaculture Society, 39(4): 521-527.

Roe, C. 2016. Improving High Soy Feed Formulations for Florida Pompano Trachinotus carolinus through Phytase Supplementation. In Fisheries, Aquaculture and Aquatic Sciences, Auburn University, Auburn, Vol. Mastrs fo Science, pp. 60

Rombenso, A.N., J.T. Trushenski, and M.H. Schwarz. 2016. Fish oil replacement in feeds for juvenile Florida Pompano: Composition of alternative lipid influences degree of tissue fatty acid profile distortion. Aquaculture, 458: 177-186.

Rombenso, A.N., J.T. Trushenski, and M.H. Schwarz, M.H. 2017. Beef tallow is suitable as a primary lipid source in juvenile Florida pompano feeds. Aquaculture Nutrition, 23(6): 1274-1286. 
Rossi Jr. W. and D.A. Davis. 2012. Replacement of fishmeal with poultry by-product meal in the diet of Florida pompano Trachinotus carolinus L. Aquaculture, 338-341:160-166.

Rossi, W. and D.A. Davis. 2014a. Meat and bone meal as an alternative for fish meal in soybean meal-based diets for Florida Pompano, Trachinotus carolinus L. Journal of the World Aquaculture Society, 45:613-624.

Rossi, W. and D.A. Davis. 2014b. Meat and bone meal as an alternative for fish meal in soybean meal-based diets for Florida Pompano, Trachinotus carolinus L. Journal of the World Aquaculture Society, 45: 613-624.

Rumsey, G.L., A.K. Siwicki, D.P. Anderson, and P.R. Bowser. 1994. Effect of soybean protein on serological response, nonspecific defense mechanisms, growth, and protein utilization in rainbow trout. Vet. Imm. and Immunopathology, 41:323-339.

Salze, G., M. Rhodes, and D.A. Davis. 2014. Estimation of the quantitative requirement for dietary taurine in Florida pompano, Trachinotus carolinus, Juveniles In Aquaculture America 2014, Seattle, USA.

Salze, G.P. and D.A. Davis. 2015. Taurine: a critical nutrient for future fish feeds. Aquaculture, 437:215-229.

Salze, G.P., E. Spangler, P.A. Cobine, M. Rhodes, and D.A. Davis. 2016. Investigation of biomarkers of early taurine deficiency in Florida pompano Trachinotus carolinus. Aquaculture, 451: 254-265.

Sookying, D. 2010. Development and application of soybean based diets for Pacific white shrimp Litopenaeus vannamei. Dissertations. Fisheries and Allied Aquacultures, Auburn University.

Sookying, D., D. Davis, and F. Soller Dias Da Silva. 2013. A review of the development and application of soybean based diets for Pacific white shrimp Litopenaeus vannamei. Aquaculture Nutrition, 19: 441-448.

Tatum, W.M. 1972. Comparative growth, mortality and efficiency of pompano (Trachinotus Carolinus) receiving a diet of ground industrial fish with those receiving a diet of trout chow1 in Proceedings of the annual workshop-World Mariculture Society, Wiley Online Library, 3: 65-74.
Tibaldi, E., Y. Hakim, Z. Uni, F. Tulli, M. de Francesco, U. Luzzana, and S. Harpaz. 2006. Effects of the partial substitution of dietary fish meal by differently processed soybean meals on growth performance, nutrient digestibility and activity of intestinal brush border enzymes in the European sea bass (Dicentrarchus labrax). Aquaculture, 261:182-193.

Trushenski, J. 2015. Nutritional impacts on fish mucosa: dietary considerations. Mucosal Health in Aquaculture, 199 p.

Urán, P., J. Schrama, J. Rombout, Taverne, J. Thiele, A. Obach, W. Koppe, and J. Verreth. 2009. Time-related changes of the intestinal morphology of Atlantic salmon, Salmo salar L., at two different soybean meal inclusion levels. Journal of fish diseases, 32:733-744.

Wang, L., H. Zhou, R. He, W. Xu, K. Mai, and G. He. 2016. Effects of soybean meal fermentation by Lactobacillus plantarum P8 on growth, immune responses, and intestinal morphology in juvenile turbot (Scophthalmus maximus L.). Aquaculture, 464:87-94.

Weirich, C.R. and K.I. Riley. 2007. Volitional Spawning of Florida pompano, Trachinotus carolinus, Induced via administration of gonadotropin releasing hormone analogue (GnRHa). Journal of Applied Aquaculture, 19: 47-60.

Welch, A. 2013. Monterey Bay Aquarium Seafood Watch Farm Pompano Report. Monterey Bay Aquarium.

Williams, S., R.T. Lovell, and J.P. Hawke. 1985. Value of menhaden oil in diets of Florida pompano. Progressive Fish Culturist, 47:159-165.

Yamamoto, T., Y. Iwashita, H. Matsunari, T. Sugita, H. Furuita, A. Akimoto, K. Okamatsu and N. Suzuki. 2010. Influence of fermentation conditions for soybean mea in a non-fish meal diet on the growth performance and physiological condition of rainbow trout Oncorhynchus mykiss. Aquaculture, 309: 173-180.

Zhuo, L.C., K. Liu, and Y.H. Lin. 2014. Apparent digestibility of soybean meal and Lactobacillus spp. fermented soybean meal in diets of grouper, Epinephelus coioides. Aquaculture Research, 47(3): 1009-1012. 